\title{
Self-denigrating terms
}

We WOUld like to THANK Drs. Tsuyuki ANd Davies ${ }^{1}$ For their recent editorial about self-denigrating terms used in pharmacy. Below we suggest additional terms that should be removed from the pharmacy lexicon.

Dispensing fee. Dispensing, in itself, is a technical task. It is understandable that patients may shop around for the lowest fee if they believe it is simply a matter of lick-stick-pour. What this term ignores is the cognitive aspect of dispensing, where drug therapy problems are identified and managed. Patients are paying for this professional service, so let's call it what it is-a professional fee. Better yet, when patients inquire about the pharmacy's fee, we can use the opportunity to inform them about the services that fee covers beyond dispensing.

"Extending" a prescription or "loaning" tablets. When a pharmacist renews a prescription, he or she takes professional and legal responsibility for that action based on an assessment of its appropriateness. This is not simply a passive extension of another prescriber's order but an independent therapeutic decision that occurs after assessing a patient. In other words, it is prescribing. Since pharmacist adaptations and renewals must be documented in writing, consider writing the prescription in front of the patient so he or she can see the application of our expanded scope.

Accepted recommendations. It is not unusual in the pharmacy practice literature to see the proportion of recommendations accepted as an outcome measure. Is this a fair evaluation of the quality of our advice? There are many reasons why a pharmacist's recommendation may not be accepted, apart from its validity. Not all great recommendations are accepted, and not all poor recommendations are denied. If we truly are the drug therapy experts, evaluation of our worth should not be delegated to another profession.

Your prescription will be ready in $\mathbf{5}$ minutes. Two of the most common questions faced in community pharmacy are as follows: 1) How much will it cost, and 2) How long will it take? While the first answer is often beyond our control, the second isn't. Our instinct is often to try to make the wait as short as possible, viewing community pharmacy as a service-oriented profession. But when lattes at your local café take longer than prescriptions, who are we serving? As mentioned last month, there is a distinct difference between a customer and a patient. ${ }^{1}$ A customer is provided a product, whereas a patient is provided care. It takes time for the pharmacist to review orders for appropriateness, perform a quality medication review, administer an injection and so on. From our experience, most patients who are made aware of the clinical activities that occur behind the counter are willing to wait to ensure they're done properly.

Free. Pharmacists are increasingly being paid for professional services by government and third-party payers. ${ }^{2,3}$ Are we doing ourselves a disservice by advertising these as "free"? They aren't free-as they're being paid for by an external payer-and our time is valuable. Free may also imply reduced quality, as in "You get what you pay for." As providers of high-quality professional advice, the term no charge may be preferred, ideally using the opportunity to inform our patients that some of our services, like those of physicians, nurses and so forth, are valued and funded through our universal health system.

Our scope and professional roles are expanding. We believe these small, but significant, changes will better reflect our position as drug therapy experts and patient care providers.

-Sherilyn K. D. Houle, BSP, PhD Assistant Professor School of Pharmacy, University of Waterloo Kelly A. Grindrod, BScPharm, ACPR, PharmD, MSc Assistant Professor School of Pharmacy, University of Waterloo

\section{References}

1. Tsuyuki RT, Davies NM. Self-denigration in pharmacy: words to banish from the pharmacy lexicon. Can Pharm J (Ott) 2014;147:197-9.

2. Houle SKD, Grindrod KA, Chatterley T, et al. Publicly funded remuneration for the administration of injections by pharmacists: an international review. Can Pharm J (Ott) 2013;146:353-64.

3. Houle SKD, Grindrod KA, Chatterley T, et al. Paying pharmacists for patient care: a systematic review of remunerated pharmacy clinical care services. Can Pharm J (Ott) 2014;147:209-32.

(C) The Author(s) 2014

DOI: $10.1177 / 1715163514552645$ 